\title{
Thermoelectric property features of PbTe monocrystalline and polycrystalline films
}

\author{
D.M. Freik, R.I.Zapukhlyak, M.A. Lopjanka, G.D. Mateik, R.Ya. Mikhajlonka \\ Precarpathian V.Stefanik University, 284000 Ivano-Frankivs'k, Ukraine
}

\begin{abstract}
The equations of a regression were obtained by methods of mathematical planning of manyfactors experiments. These equations determine a dependence of thermoelectric parameters of $\mathrm{PbTe}$ thin films prepared by hot wall the method from technological factors: temperatures of evaporation, walls of the chamber and deposition. PbTe thin films were layed sieged on pins (111) of $\mathrm{BaF}_{2}$ monocrystals and on amorphous polyamid fillet PM- 1 . The ranges of change of these thermoelectic parametres were determined. They respond to the best values of thermoelectric parameters of $\mathrm{PbTe}$ thin films. It is shown that the value of thermoelectric parameters of $\mathrm{PbTe}$ thin polycrystalline films is bigger in several times then the monocrystalline ones.
\end{abstract}

Keywords: telurides of lead, thin films, thermoelectric properties, monocrystal, polycrystal.

Paper received 06.07.99; revised manuscript received 11.10.99; accepted for publication 18.10.99.

\section{Introduction}

Lead chalcogenides are promising materials for thermoelectric transducers operating in a mean temperature range [12]. PbTe differs favourably from the rest ones by the electrical properties itself.

Numerous investigations of structure and electrical properties of PbTe thin films [5-11] deposited in vacuum both on monocrystalline [5-7] and polycrystalline [8-11] substrates were fulfilled. Some of them were devoted to the thermoelectric parameters of the films grown on polyamide $[10,11]$. Despite these studies any comparative characteristics of basic thermoelectric properties of thin PbTe films with various structural perfection are absent today. Besides, any data concerning the thermoelectric parameters optimization for both monocrystalline and polycrystalline films grown from a vapour phase by hot wall the method are not yet known.

In this connection, dependences of the thermoelectric properties of $\mathrm{PbTe}$ thin films deposited on monocrystalline and amorphous substrates by the hot wall method on the technological factors, used when growing samples from vapour phase, are investigated in this work by means of a manyfactors mathematical planning method, and comparison of the optimal theoretical thermoelectric parameters with the experimental ones is also discussed.

\section{Experimental procedure}

$\mathrm{PbTe}$ thin films grown from a vapour phase by the hot wall method [12] were investigated. As substrates the cleaved
(111) $\mathrm{BaF}_{2}$ monocrystals and amorphous polyamide films PM-1 were used. The deposition rate was 3-9 $\mathrm{nm} / \mathrm{s}$ and typical film thicknesses were 5-10 $\mu \mathrm{m}$.

In order to describe the dependence of thermoelectric properties of $\mathrm{PbTe}$ thin films on the technological factors by means of a mathematical planning method the global polynomial models in a three-factor hyperspace [13] were constructed. As varied factors a substrate temperature $\left(T_{S}\right)$ as well as the evaporator temperature $\left(T_{E}\right)$ and that of the chamber walls $\left(T_{W}\right)$ were chosen.

As the optimization parameters the thermo-e.m.f. coefficient $(\alpha)$, electrical conductivity $(\sigma)$, thermoelectric power $\left(\alpha^{2} \sigma\right)$, and thermoelectric quality factor $\left(Z=\alpha^{2} \sigma / \chi\right.$, where $\chi$ - is the thermal conductivity) were used.

The check-up of both the hypothetical models and the regression coefficient dependences adequacy was carried out in accordance to Fhisher's and Student's criteria at $5 \%$ confidence level, respectively [14].

Electrophysical parameters of the films were measured potentiometricaly in stationary electrical and magnetic fields. Thermal conductivity coefficients were determined using the procedure proposed in [15]. Chemical and phase compositions as well as the film structural perfection were checked up by the electron-probe and X-ray methods [16].

\section{Experimental results and discussion}

PbTe films grown on the cleaved (111) $\mathrm{BaF}_{2}$ monocrystals (type I) at the $T_{E}, T_{W}$ and $T_{S}$ temperatures had the (111) plane orientation parallel to a substrate surface. Linear dimensions of the monocrystal blocks in these films were in 


\section{D.M. Freik et al.: Thermoelectric property features of PbTe monocrystalline...}

the range of $0.5-1.5 \mathrm{~cm}$ and the mosaic structure was limited by $1.5-3 '$. For the films of PbTe grown on a polyamide substrate (type II) the polycrystalline structure with the grains between 7-80 $\mu \mathrm{m}$ was observed without any orientation. All films had the $n$-type conductivity with carrier concentration in the range of $(0.5-3.5) \cdot 10^{17}$ and $(5-25) \cdot 10^{17} \mathrm{~cm}^{-3}$, and with the carrier mobility of $(0.3-4.2) \cdot 10^{4}$ and $(2.2-2.8) \cdot 10^{3} \mathrm{~cm}^{2} \cdot \mathrm{V}^{-1} \cdot \mathrm{s}^{-1}$ at $77 \mathrm{~K}$ for the types I and II, respectively.

Dependence of the thermoelectric parameters on the technological factors is described by a second order equation (Figs 1,2). Obtained in such way technological factors providing the maximal thermoelectric parameters of $\mathrm{PbTe}$ films are listed in Table.

Table. Optimal values of the thermoelectrical parameters of monocrystalline and policrystalline PbTe films and the technological factors used in the course of growing them from a vapour phase in the hot wall method.

\begin{tabular}{|c|c|c|c|c|c|}
\hline \multirow{3}{*}{$\begin{array}{l}\text { Optimization } \\
\text { param eters }\end{array}$} & \multicolumn{4}{|c|}{ Optimal values } & \multirow{3}{*}{$\begin{array}{l}\text { Experi- } \\
\text { mental } \\
\text { values }\end{array}$} \\
\hline & \multicolumn{3}{|c|}{ Factors } & \multirow{2}{*}{$\begin{array}{c}\text { Parame- } \\
\text { ters }\end{array}$} & \\
\hline & $\begin{array}{c}T_{S}, \\
\mathrm{~K}\end{array}$ & $\begin{array}{c}T_{E}, \\
\mathrm{~K}\end{array}$ & $\begin{array}{c}T_{W}, \\
\mathrm{~K}\end{array}$ & & \\
\hline \multicolumn{6}{|c|}{ Type I, substrates are spalling of (111) $\mathrm{BaF}_{2}$} \\
\hline$\alpha, \mu V \cdot \mathrm{K}^{-1}$ & 473 & 818 & 953 & 145 & 152 \\
\hline$\sigma, \mathrm{Om}^{-1} \cdot \mathrm{cm}^{-1}$ & 473 & 818 & 973 & 417 & 410 \\
\hline$\alpha^{2} \sigma, \mathrm{W} \cdot \mathrm{K}^{-2} \mathrm{~cm}^{-1}$ & 473 & 818 & 973 & $1.9 \cdot 10^{-5}$ & $1.7 \cdot 10^{-5}$ \\
\hline$Z, \mathrm{~K}^{-1}$ & 473 & 818 & 973 & $0.7 \cdot 10^{-3}$ & $0.6 \cdot 10^{-3}$ \\
\hline \multicolumn{6}{|c|}{ Type II, substrates are PM-1 } \\
\hline$\alpha, \mu \mathrm{V} \cdot \mathrm{K}^{-1}$ & 453 & 759 & 843 & 314 & 321 \\
\hline$\sigma, \mathrm{Om}^{-1} \cdot \mathrm{cm}^{-1}$ & 453 & 759 & 833 & 437 & 415 \\
\hline$\alpha^{2} \sigma, \mathrm{W} \cdot \mathrm{K}^{-2} \mathrm{~cm}^{-1}$ & 453 & 759 & 823 & $4.4 \cdot 10^{-5}$ & $4.3 \cdot 10^{-5}$ \\
\hline$Z, \mathrm{~K}^{-1}$ & 453 & 759 & 823 & $3.6 \cdot 10^{-3}$ & $3.7 \cdot 10^{-3}$ \\
\hline
\end{tabular}

Electrical properties of $\mathrm{A}_{4} \mathrm{~B}_{6}$ compounds are determined by deviation from stoichiometry in a homogeneity range [3]. In our case of $\mathrm{PbTe}$ evaporation, the steam and, respectively, condensate are enriched by the metal component at the cost of the batch transition to the composition with the general pressure minimum as well as to its impoverishment by lead [7]. It is this fact that gives us an opportunity to grow the films of an electronic type at any changes of technological factors $T_{E}$ and $T_{S}$. As to the influence of the technological factors on the processes of defects formation in the thin $\mathrm{PbTe}$ films the following can be pointed out. The increase of the deposition temperature $T_{S}$ diminishes the electron concentration owing to the more fast decrease of the interstitial $\mathrm{Pb}$ atoms concentration than that of the charged lead vacancies [17]. Besides, the tendency of thermoelectric parameters to pronounce the parabolic dependence on technological factors (Figs 1,2) is caused by the changes of the structural characteristics and by the dependence of the carriers mobility on their concentration [7].

Optimal values of the electrophysical parameters calculated theoreticaly are well agreed with the experimental ones (Table).

It engages our attention that the polycrystalline $\mathrm{PbTe}$ films deposited on polyamide have higher values of thermo- e.m.f. coefficients (Fig. 2,a) in comparison with the monocrystalline ones on $\mathrm{BaF}_{2}$ substrates (Fig. 1,a; Table) as well as the values of other derivative thermoelectric parameters (Table). A degree of the structural perfection of the condensate is the most essential reason of this phenomenon. Polycrystalline films on polyamide possess by more strongly advanced structure between the grains. The energy barriers arise on the grain boundaries. Owing to the selective scattering on this potential barriers electrons with the energies smaller than the Fermi one do not participate in transport phenomena. The high-energy carriers keep their free path like that in the defectless crystal, i.e. they pass through the
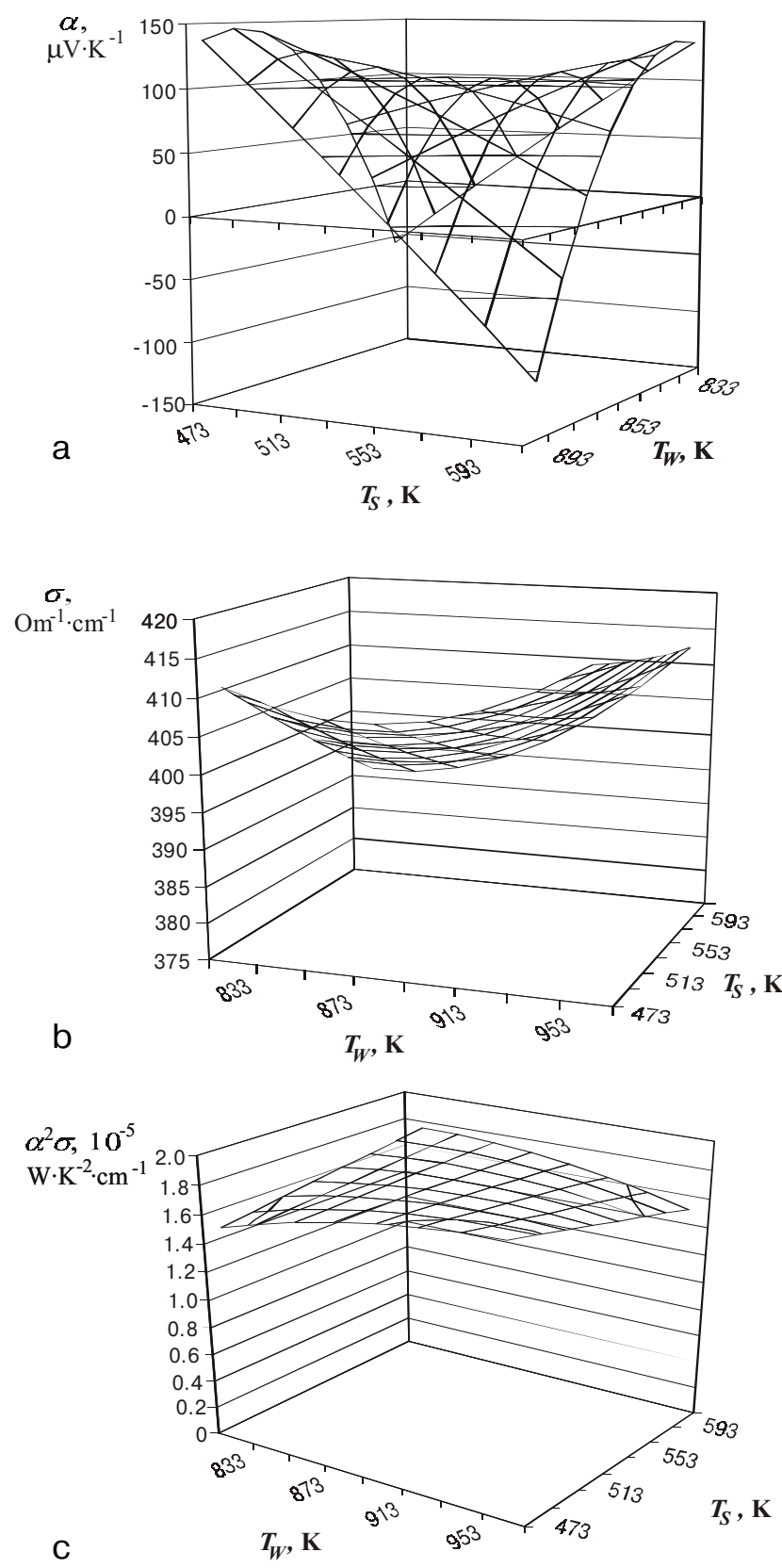

Fig.1. Hypersurfaces of the response for the thermo-e.m.f. coefficient, $\alpha$ (a), electroconductivity, $\sigma$ (b), and thermoelectrical power, $\alpha^{2} \sigma$ (c), of PbTe thin films on the (111) $\mathrm{BaF}_{2}$ at $T_{E}=818 \mathrm{~K}$. 


\section{D.M. Freik et al.: Thermoelectric property features of PbTe monocrystalline...}
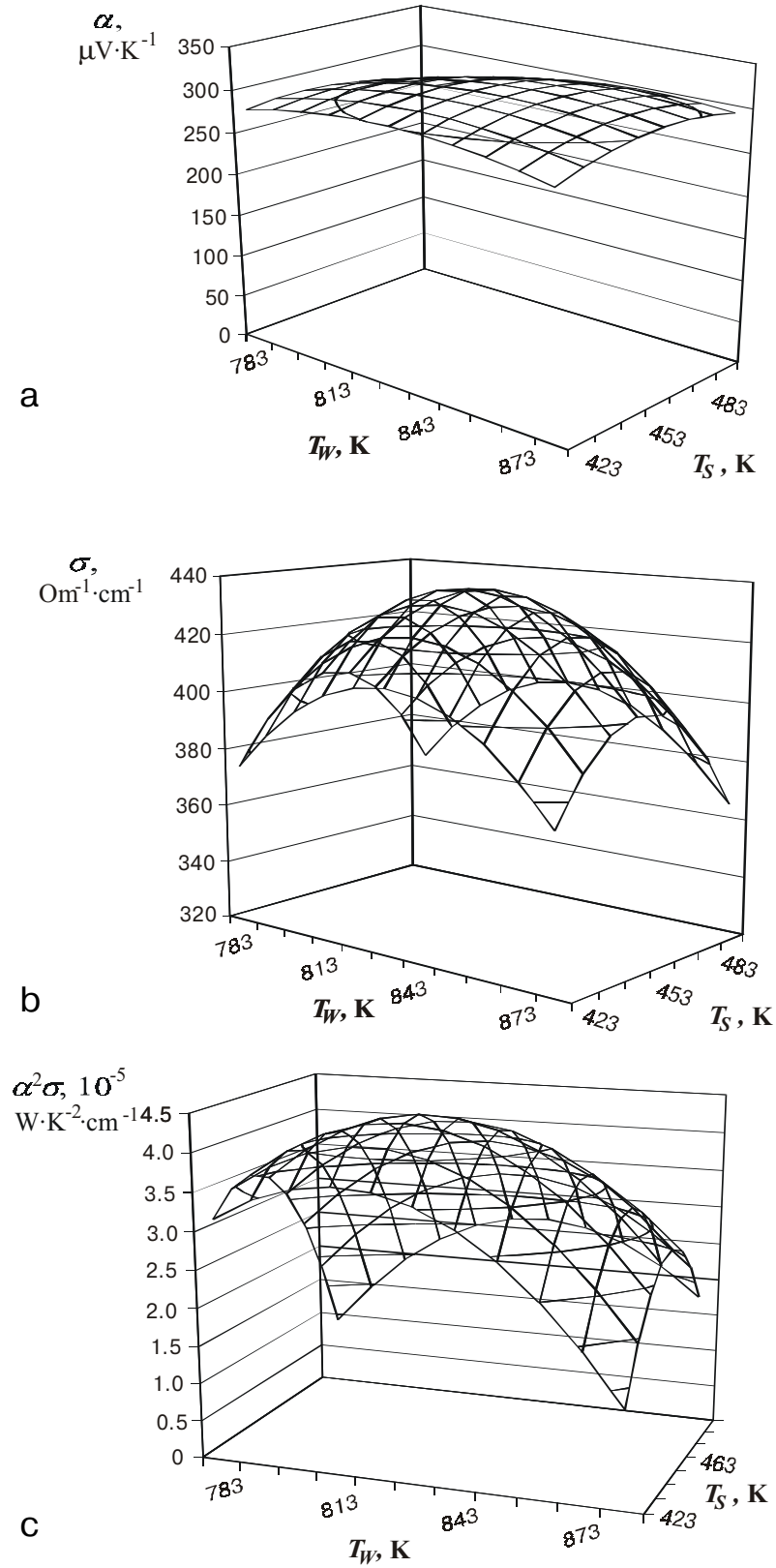

Fig. 2. Hypersurfaces of the response for the thermo-e.m.f. coefficient $\alpha$ (a), electroconductivity, $\sigma(\mathrm{b})$, and thermoelectrical power, $\alpha^{2} \sigma(\mathrm{c})$, of PbTe thin films on polyamide at $T_{E}=759 \mathrm{~K}$.

barriers $[8,9]$. In this case conductivity is somewhat decreased (Fig. 2,b), and the thermo-e.m.f. coefficient grows (Fig. 2,a). As the thermoelectric parameters are proportional to the square of thermo-e.m.f. $\left(\alpha^{2}\right)$ their considerable improvement is observed (Table).

Now let us discuss the thermal conductivity, which determines $Z$-value. It should be noted, that the whole thermal conductivity $(\chi)$ of lead chalcogenides can be represented by a sum of lattice $\left(\chi_{l}\right)$ and electronic $\left(\chi_{e}\right)$ components $[2,18]$. Our optimism concerning the use of the thin-film thermoelectric material is amplified by the fact that the dispersity decreases the thermal conductivity $[2,18]$. The free path of phonons in lead chalcogenides at the nitrogen temperatures is close to $1 \mu \mathrm{m}$ [19]. Since the average sizes of the grains in $\mathrm{PbTe}$ films on polyamide are of the same order the boundary scattering effect of phonons leads to the decrease of thermal conductivity [19]. Microstresses and microcracks which are caused by the difference between temperature expansion coefficients of the film and the substrate also lead to decreasing the thermal conductivity of the films. As the difference between the experiment temperature and that of deposition is rised the influence of macrodefects grows. Besides, in finely dispersed materials the contribution of electrons to the thermal conductivity is smaller due to their scattering on the boundaries of the grains and the total thermal conductivity of such polycrystal coincides with the lattice one.

Thus, the increase of the thermo-e.m.f. coefficient $(\alpha)$ and the decrease of the thermal conductivity $(\chi)$ of the PbTe polycrystalline films leads to the considerable rise of their thermoelectric parameters in comparison with the monocrystalline films and improve parameters of the devices based on these films.

\section{Conclusion}

Optimal values of the thermoelectric parameters of the thin $\mathrm{PbTe}$ films grown from a vapour phase by the hot wall method on the cleaved (111) $\mathrm{BaF}_{2}$ monocrystals and amorphous polyamide substrates were determined. It was found that the thermoelectric power and the thermoelectric quality factor of the polycrystalline films are of 2-5 times higher than those of the monocrystalline ones.

\section{References.}

1. Ioffe A.F. Semiconductor materials.-M.-L.: AN SSSR.-1960 (in Russian).

2. Anatychuk L.I. Thermoelements and thermoelectric devices. Reference-book.-Kiev: Naukova dumka.-1979.-768 p.(in Russian).

3. Abrikosov N.H., Shelimova L.E. Semiconductors materials based on $\mathrm{A}^{\mathrm{IV}} \mathrm{B}^{\mathrm{VI}}$ compounds.- M.: Nauka.-1975.- 194 c. (in Russian).

4. Ravich Yu.M., Efimova B.A., Smirnov N.A. Investigations methods of semiconductors in application to the lead chalcogenides $\mathrm{PbTe}, \mathrm{PbSe}$, PbS.- M.: Nauka.-1968.-384 p. (in Russian).

5. Voronina I.P., Semiletov S.A. Structure and electrophysical properties of the monocrystal PbTe films.- Solid State Phys.-1964.- 6, N 6.- P. 1898-1900 (in Russian).

6. Lopez-Otero A. The use of a phase diagram as a guide for the growth of PbTe films //Appl. Phys. Lett.-1975.-26, N8. P. 470-472.

7. Freik D.M., Galuschak M.A., Mezilovskaya L.I. Physics and technology of semiconductor films.-Lviv: Vyshcha shkola.-1988.-152 p. (in Russian).

8. Palatnik L.S., Sorokin V.K., Pravdina O.V. Investigation of thermoe.m.f. of PbTe films // Izv. AN SSSR. Neorgan. Materialy.-1981.- 17, N 6.-P.958-961 (in Russian).

9. Bojkov Yu.A., Kutasov V.A. Electrophysical properties of policrystalline PbTe films.// Solid State Phys.-1983.- 28, N12.- P. 3489-3491 (in Russian).

10. Uhlinov G.A., Lakhno I.G. Influence of the different metal covers on the thermoelectrical properties of PbTe films // Izv. AN SSSR. Neorgan. Materialy.- 1984.- 20, N 5.- P. 765-768.

11. Atakulov Sh.B., Konanbaev I.M. Electrophysical properties of polycrystalline $n$-PbTe films at $\gamma$-irradiation // Semiconductor Phys. and Techn.-1987.-21, N 1.- P. 150-152 (in Russian). 


\section{D.M. Freik et al.: Thermoelectric property features of PbTe monocrystalline...}

12. Freik D.M. Preparation of $\mathrm{A}^{\mathrm{IV}} \mathrm{B}^{\mathrm{VI}}$ films// Devices and Techn. of Experiment.- 1976.-N5.-P.7-17 (in Russian).

13. Adler Yu.P. Markova E.V., Granovskij Yu.V. Planning of the experiment at the search of the optimal conditions. - M.: Nauka. - 1971.282 p. (in Russian).

14. Nalimov V.V., Chernova N.A. Statistic methods of the planning of experiment.-M.: Nauka.- 1965.-132 p. (in Russian).

15. Bojkov Yu.A., Goltsman B.M., Sinenko S.F. The method for determination of the thermoconductivity of the thin films // Devices and Techn. of Experiment.- 1975.-N2.-P.230-232 (in Russian).
16. Mikhajlov I.F., Alaverdova O.G., Fuks M.Ya. The method of the sdudy of structural crystal perfection by means of analysis of X-ray curves (in Russian) Zavodskaya laboratoriya.-1980- 46, N1.- P.27-31.

17. Directed synthesis and formation of the defects in thin films of $\mathrm{PbTe}$ //Freik D.M., Prokopiv V.V., Nych A.V. and others // Materials Science Engineering.- 1997.-B48, P. 226-228.

18. Iordanishvili V.E., Bojkov V.A., Kutasov V.A. Thermoconductivity of $\mathrm{PbSnSe}$ films condensed at different temperatures (in Russian) // Solid State Phys.- 1983.- 28, N1.- P. 263-265. 